\title{
Stress and Deflection of a Concrete Block in a Four-Point Bending (FPB) Test
}

\author{
Waluyo Adi Siswanto*, Bayu Putra Martama \\ Department of Mechanical Engineering, Universitas Muhammadiyah Surakarta, Indonesia
}

Received August 13, 2019; Revised October 21, 2019; Accepted October 28,2019

Copyright $\bigcirc 2019$ by authors, all rights reserved. Authors agree that this article remains permanently open access under the terms of the Creative Commons Attribution License 4.0 International License

\begin{abstract}
This study aims to identify the stress concentration and distribution pattern in the mid-cross-section of a concrete block in a four-point bending (FPB) test with notch and without notch using a finite element method (FEM). The research was preceded by a meshing sensitivity analysis (MSA) with verification of reference from FPB test deflection theories. The selected finite element model was then used for numerical FPB testing with load variants of $100 \mathrm{kN}, 200 \mathrm{kN}$ and $300 \mathrm{kN}$. Simulation test results show that the greatest stress and deflection of the model from the FPB simulation with notch occur in the mid-bottom area, while in the model without notch the strongest stress takes place in the mid-bottom area and the largest deflection in the mid-center area. The influence of load variation indicates that the greater the load, the greater the stress concentration and deflection around the notch. Simulation by FEM can replace real material tests by means of the finite element model applied in this study.
\end{abstract}

Keywords Four-Point Bending, Concrete Block, Initial Notch Crack, FEM

\section{Introduction}

One way to increase the quality standards of concrete construction is by material testing, which is an important process in selecting a material [1]. This material testing is performed to identify the strength and toughness levels of the material when receiving a load or force in construction [2].

A bending test is a destructive treatment that tests the material by bending it. There are two types of loading for such test, namely three-point bending (TPB) and four-point bending (FPB). A bending test undergoes axial/normal stress as the direction of the force is perpendicular to the cross-section. Axial/normal stress prompts a normal force and bending moment, which in turn cause deflection [3].

FPB tests are generally applied in concrete block testing with a solid specimen [4], but FPB application in testing concrete with an initial notch crack situated in the mid-bottom area of the specimen is still rarely used in concrete construction [5].

Concrete is one of the most commonly used materials in building construction throughout the world. The vast use of concrete in every aspect of building construction strongly requires accurate treatment in order to obtain high-quality concrete structures and raise productivity [6].

Studies on concrete bending tests have been conducted through numerous field experiments. Referring to prior research [7], Yin et al. experimented with a concrete block FPB test according to ASTM E399 standards [8] with varied initial notch crack ratios $(0.2-0.6)$ on five concrete specimens. The material properties of the concrete included $2400 \mathrm{~kg} / \mathrm{m}^{3}$ density and an elastic modulus of $32.46 \mathrm{GPa}$. The current study employed the same model as that of Yin et al. [7] but with a numeric simulation based on finite element analysis (FEA).

For this research two FPB test simulation models were built, namely a model with notch at an initial crack ratio of 0.2 and one without notch. The finite element method system implemented was Mecway FEA version 12 .

This study seeks to determine the ratios of stress concentration and deflection between both models at loads of 100,200 and $300 \mathrm{kN}$, and to observe the distribution patterns of deflection and stress in the mid-cross-section area of the concrete block, as undertaken in prior research [9].

This simulation method research serves as preliminary analysis and prediction of an experiment assumed to be more cost-efficient than others. Many popular engineers today have involved such simulation method in their research. 


\section{Literature Review}

Peng et al. [10] conducted an experiment using concrete blocks with variation in aggregate size to identify fractures and damages in the material. FPB tests on concrete blocks with initial notch crack by FEM simulation were carried out to alter the form of experiment [5]. Research by Chen et al. [11] created a simulation model using the finite element method (FEM) software ABAQUS Explicit Solver. FEM simulation was employed to observe deformation of the crack in concrete [12]. The experiment outcomes showed that the smaller the aggregate size, the smaller the damage to the material. During the development of crack growth, is involves high stress concentration that coarse grains tend to have more damage due to the higher stress to continue the crack.

Experimentally, concrete blocks can be tested by TPB with notch at an initial crack ratio range of 0.2 to 0.85 as found in the source [13]. This test can be used to obtain the mechanical properties of the material [11]. Results of the TPB experiment uncovered that the notch ratio of $0.2 \mathrm{had}$ the largest load and exhibited the greatest resistance to cracking. A Chinese GB175-2007 standard TPB test indicated that the specimen with a notch ratio of 0.2 had the greatest cracking resistance and fracture energy [14]. Thus, it can be concluded that the specimen with small initial notch crack will cause damage to the material.

An experiment on concrete cubes with notch at an initial crack ratio range of 0.2 to 0.4 has been attempted [15]. It was concluded from the results that the specimen with a notch ratio of 0.2 had the greatest load and fracture energy, implicating that the smaller the notch, the greater the load and fracture energy. Outcomes of the experiment [16] provide a comparison and verification of the results of FEA methods. The simulation model with notch showed that the greater the size of the notch, the greater the material damage.

\subsection{Von Mises Stress}

Song et al. [17] undertook an experiment on reinforced concrete material simulated by ANSYS software to predict the greatest stress concentration which causes material damage. The FEA method was used to analyze the stress concentration in the cross-section of the middle area of the tested specimen [18]. This variable determination was based on the fact that in this area stress distribution occurs, ranging from normal stress to maximum stress in concrete FPB testing [19].

Lee and Lopez [20] conducted an experimental study of concrete block with initial notch crack. The test implemented ASTM C496 standard TPB aimed to determine stress concentration in the initial notch crack of the material. Research by Ding and Bai [21] sought to measure the fracture energy (Gf) of the material. A 3D TPB simulation model made with ABAQUS software on reinforced concrete blocks was proven very effective [22], while a 2D model using ANSYS software to investigate the fracture phenomena of stress interaction due to the effects of initial notch crack can be found in the source.

\subsection{FPB Deflection Theories}

Deflection is the change in shape of the block on the $y$-axis (vertical direction) caused by vertical loads applied to the block or beam. Murray et al. [23] studied reinforced concrete material block model 159 using the FEA software LS-DYNA beta version 197. The deflection of a beam is due to the normal and axial stresses which lead to bending moment [3]. The execution of the FPB test, illustrated in Figure 1, aimed to gauge stress concentration and deflection of the material.

Figure 2 depicts the load distribution of the FPB test and deflection of the specimen. Figure $2 b$ shows the distribution of maximum deflection to the load received.

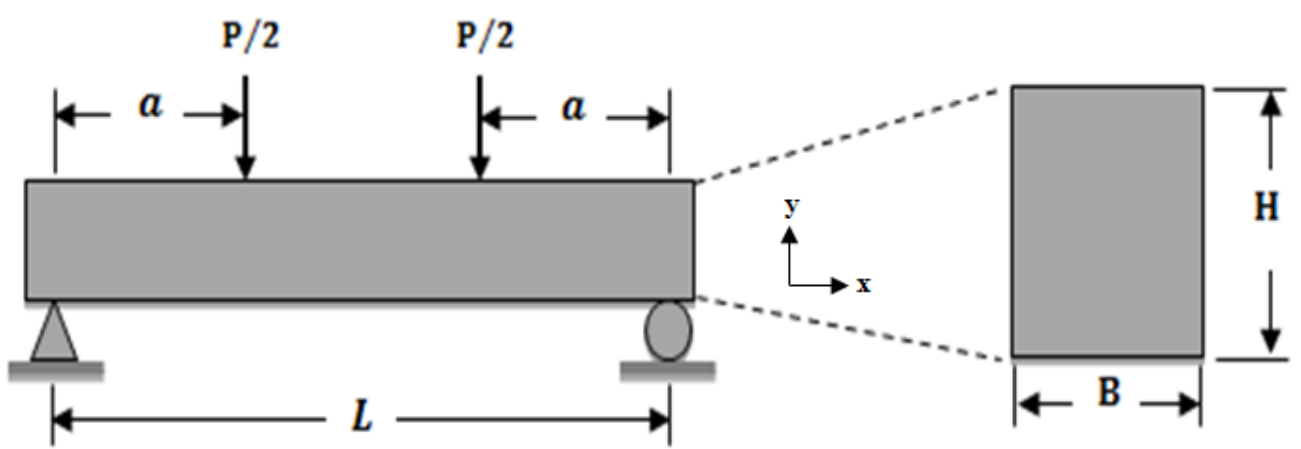

(a). Concrete block bending test

(b). Block cross-section

Figure 1. FPB Test Configuration 


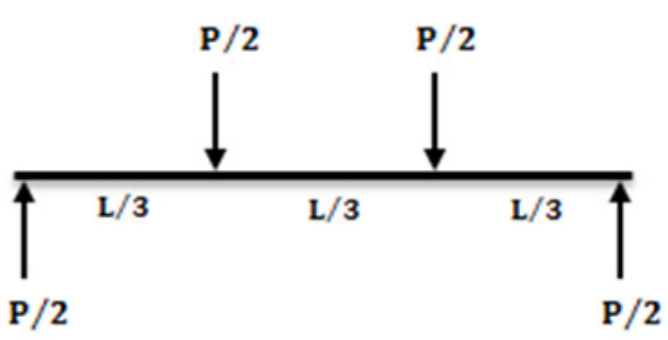

(a). Free body diagram FPB Test

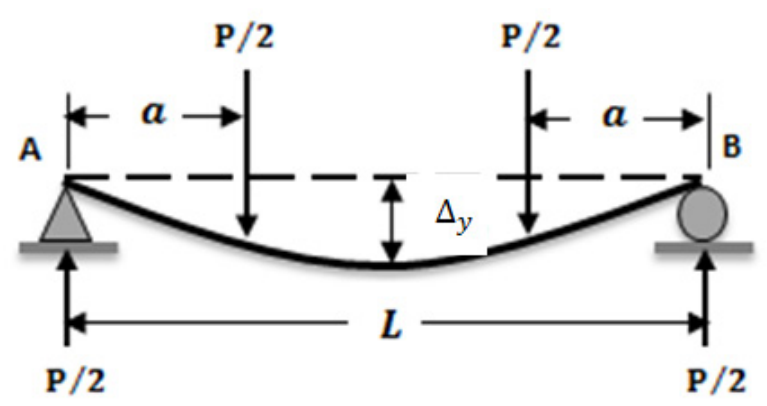

(b). Deflection distribution

Figure 2. Load and deflection distributions

Maximum Deflection $\left(\Delta_{y}\right)$

$$
\Delta_{y}=\frac{P a}{24 E_{I}}\left(4 a^{2}-3 L^{2}\right)
$$

Moment of Inertia (I)

$$
I=\frac{B H^{3}}{12}
$$

$P$ represents the load $(\mathrm{kN}), \mathrm{E}=$ elastic modulus $(\mathrm{GPa}), \mathrm{I}$ $=$ moment of inertia, $\mathrm{a}=$ distance from edge to load point $(\mathrm{mm})$, and $\mathrm{L}=$ total specimen length $(\mathrm{mm})$. Figure $1 \mathrm{~b}$ displays the cross-section geometry of the concrete block, in which $\mathrm{H}=$ block height $(\mathrm{mm})$ and $\mathrm{B}=$ block width $(\mathrm{mm})$ [24]. The formulas above are only applicable for FPB of a rectangular cross section of a beam without notch.

\subsection{FPB Testing with Notch}

The FEA simulation method can be implemented in FPB testing [5]. Mardalizad et al. [25] carried out ASTM D7012-04 standard FPB test research on concrete block material with notch using FEM software ABAQUS and LS-DYNA to determine and investigate material strength in the middle area of the cross-section of the specimen, by using dynamic-explicit approach, while in this research the simulation approach is quasi-static.

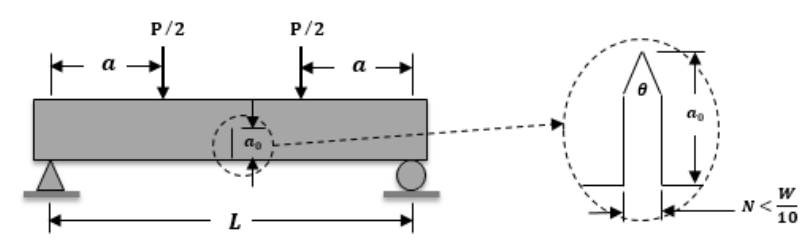

Figure 3. FPB testing with notch

Figure 3 above describes the geometry of concrete block FPB testing with notch, including $\mathrm{W}(\mathrm{W}=\mathrm{B})$, or the cross-section width of the specimen, the width of the notch $(\mathrm{N})$, the angle $\left(\theta<90^{\circ}\right)$ (ASTM E399), the length of the initial notch crack $\left(\mathrm{a}_{0} / \mathrm{H}=0.2\right)$, and $\mathrm{H}$, which denotes the height of the specimen's cross-section [7].
Cao and Zhang [26] undertook a study using the FEM software ABAQUS version 6.11 to identify the cracking behavior of concrete blocks material with initial notch crack. Research by Garcia et al. [27] implemented an FPB test according to ISO 12108 on concrete blocks with initial crack single notch. FPB testing on concrete blocks with initial notch crack focused on the middle part of the specimen as the stress concentration point [19].

\section{Methodology}

This study used a simulation method to analyze stress and deflection in an FPB test. This research used a simulation method to analyze stress and deflection in FPB test. The FPB test consists of two cases, i.e. with notch and without notch. The FPB without notch

In order to verify the simulation tool (Mecway) and to gain the best simulation FEM model, verification was carried out first using a simple FPB un-notched model which is similar with bending theories to ensure that the simulation device employed produces correct predictions in accordance with the theories.

After obtaining verification results affirming that the software can be used, meshing sensitivity analysis (MSA) was conducted to choose the most appropriate FPB model. Several meshing models were FPB tested and observed with deflection parameters. The selected model was the one with stable deflection and proximity to theoretical bending outcomes in un-notched slender beam specimens.

\subsection{Testing Experiment}

This research involved homogenous (isotropic) unreinforced concrete blocks. The FPB testing followed ASTM E399 standards (1997) as depicted in Figure 4, whereas size details of the test object can be seen in Table 1. Characteristics of the utilized material adhered to material properties as in Table 2. 

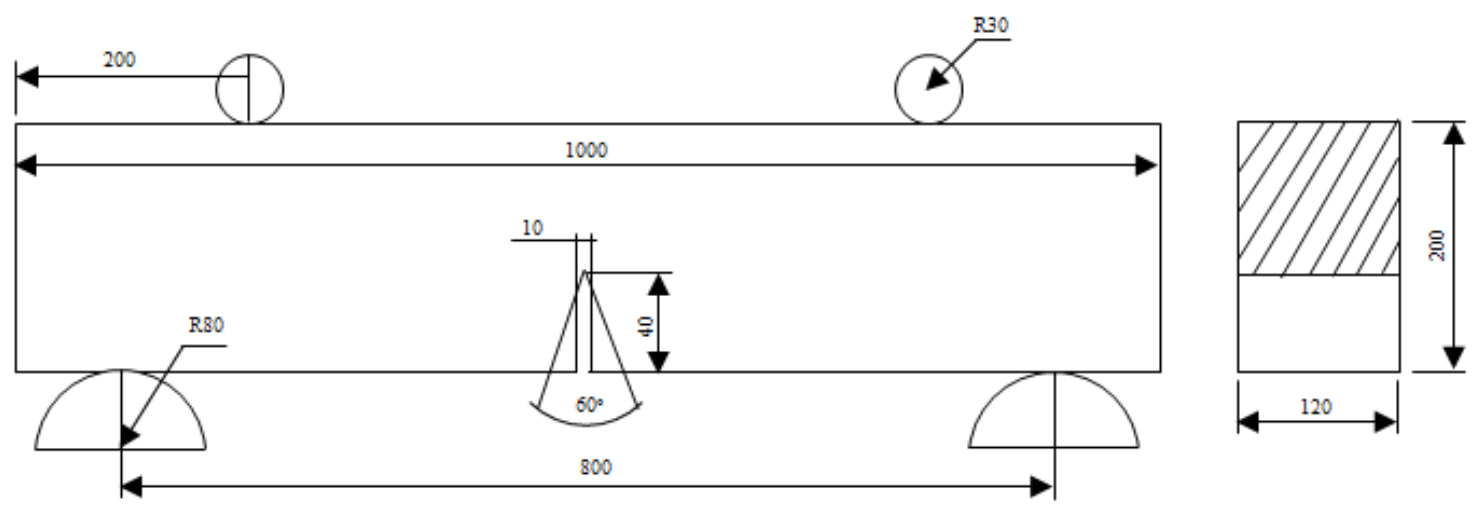

Figure 4. Geometry of FPB test concrete

Table 1. Concrete block dimensions ( $\mathrm{mm})$

\begin{tabular}{|c|c|c|c|c|c|c|c|c|}
\hline Length & Width & Height & Span & Angle & Notch depth & Notch height & Top cyl. & Bottom cyl. \\
\hline 1000 & 120 & 200 & 800 & $60^{\circ}$ & 10 & 40 & R30 & R80 \\
\hline
\end{tabular}

Table 2. Concrete property input

\begin{tabular}{|c|c|c|}
\hline Elastic modulus & Density & Poisson's ratio \\
\hline $32.46 \mathrm{GPa}$ & $2400 \mathrm{~kg} / \mathrm{m}^{3}$ & 0.15 \\
\hline
\end{tabular}

\subsection{Mid-Cross-Section}

The mid-cross-section is the middle of the cross-section of the FPB model specimen (with and without notch) as the data collection area for simulation results. This area is divided into three sections (Figure 5), each of which consists of seven section nodes.

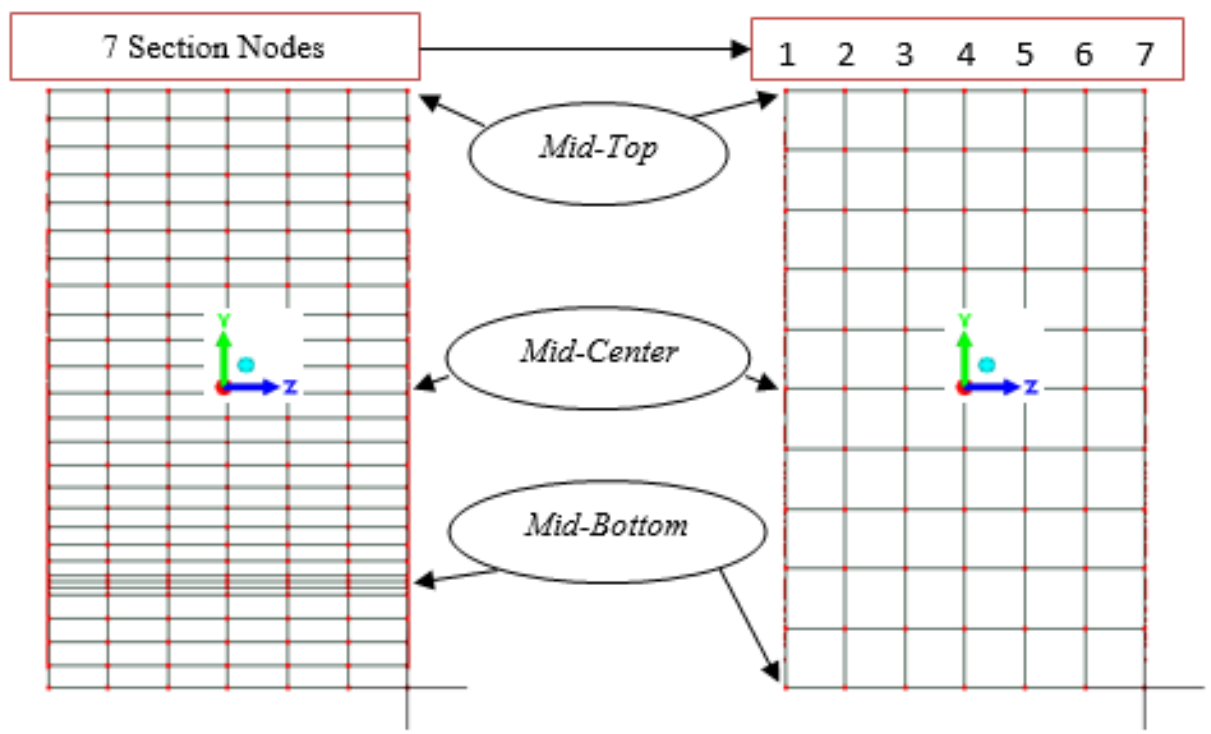

(a) Cross-section with notch

(b) Cross-section without notch

Figure 5. Mid-cross-section

\section{Results and Discussion}

\subsection{Verification Results}

The objective of the verification is to see the accuracy of the simulation FEM analysis tool Mecway, and to select the best FEM meshing for further investigation. The selected model was the FPB without notch.

Verification was carried out by comparing maximum deflection results from various FPB simulation models to 
theoretical FPB maximum deflection as defined in Eq. (1). The FPB model was produced by 3D linear static analysis with the Mecway FEA 12 software. Table 3 displays data resulting from verification of the FPB model with six geometric variants (one line and five solid). Theoretical result of the maximum deflection (Eq. 1) was taken from the source [23]. The comparison of the error (difference with theoretical value) of each FEM model are also presented in Table 3.

Table 3. Results of verification between FPB simulation model and FPB test theories

\begin{tabular}{|c|c|c|c|c|c|c|}
\hline No & Model & Element Geometry & Elements/Nodes (Element type) & Load (kN) & Maximum Deflection (mm) & Error (\%) \\
\hline 1. & FEM 1 & Line & $60 / 61($ Line 2) & 200 & 1.823 & 0.00 \\
\hline 2. & FEM 2 & Solid & $256 / 425(\operatorname{Hex} 8)$ & 200 & 1.815 & 0.43 \\
\hline 3. & FEM 3 & Solid & $224 / 375(\operatorname{Hex} 8)$ & 200 & 1.801 & 1.21 \\
\hline 4. & FEM 4 & Solid & $160 / 285(\operatorname{Hex} 8)$ & 200 & 1.846 & 1.28 \\
\hline 5. & FEM 5 & Solid & $80 / 171(\operatorname{Hex} 8)$ & 200 & 1.798 & 1.38 \\
\hline 6. & FEM 6 & Solid & $90 / 201(\operatorname{Hex} 8)$ & 200 & 1.828 & 0.23 \\
\hline & \multicolumn{2}{|c|}{ FPB deflection theory formula [23] } & $200 \mathrm{kN}$ & 1.823 & \\
\hline
\end{tabular}

The results show that the simulation tool Mecway can reproduce the simple model of FPB model by using line elements. The result of line element model is perfectly match with the simple FPB bending theory, showing no error. Since line elements cannot be used for FPB with notch, solid elements should be used instead of line elements. In solid element models (no 2 to no 6) the measurement of the maximum deflection is at the middle of cross section (center line).

Considering the lowest difference of the maximum deflection with theoretical value, FEM meshing model no 6 was then selected to be used for further investigation in notched FPB. For notched model, the basic meshing in model 6 was then refined to accommodate the present of the notch without changing the topology of the meshing. The number of solid elements used was 15,054 and the total number of nodes was 14,577.

\subsection{Von Mises Stress}

The von Mises stress of the FPB test with notch and without notch is depicted in Figure 6. The comparison is the maximum Von Mises stress at the middle surface.
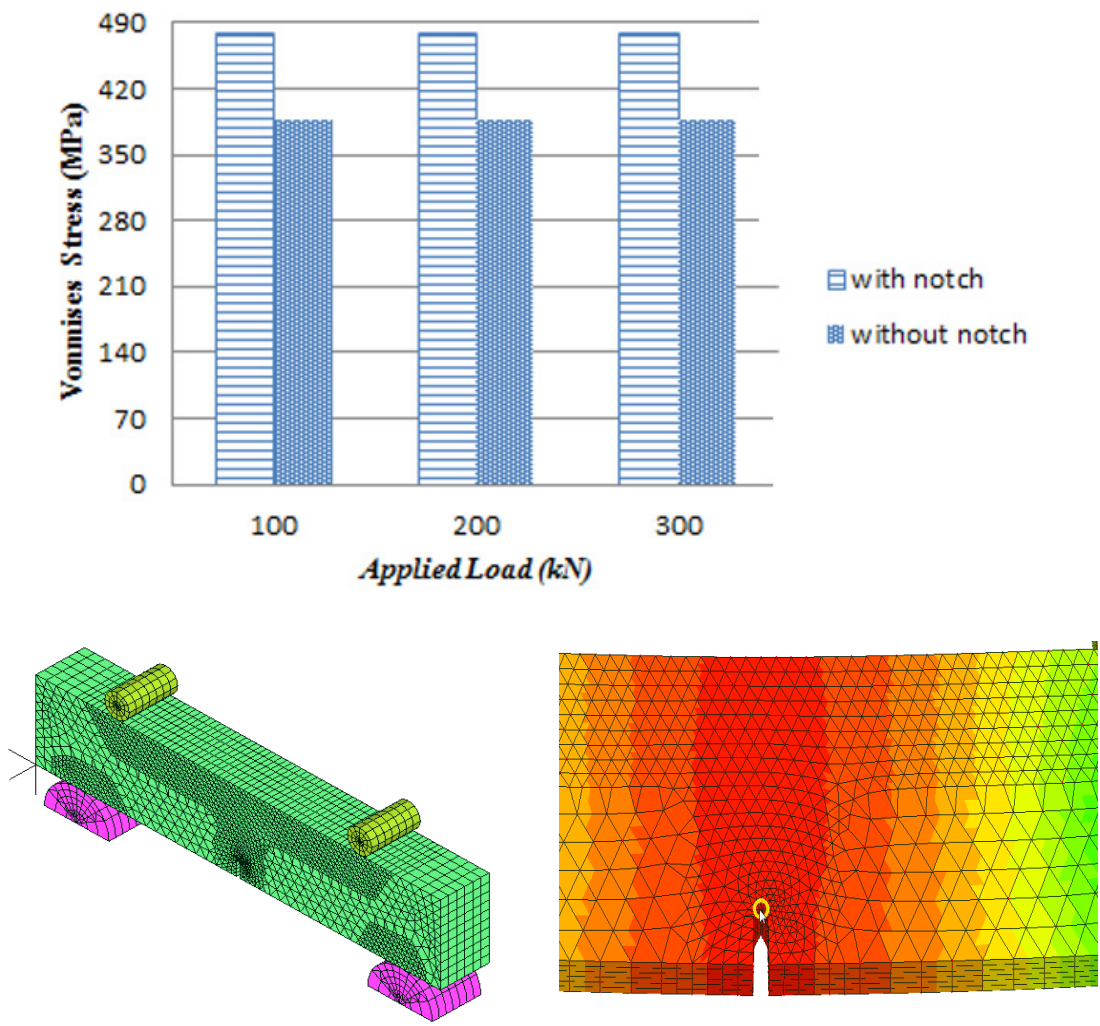

Figure 6. Von Mises stress against load variation 
The stress concentration of the FPB model with notch is higher than without notch. The presence of the notch at the bottom, increased significantly the stress level represented in the middle layer of the block. In notched condition the loading range from $100 \mathrm{kN}$ to $300 \mathrm{kN}$ increased the stress only $0.24 \%$.

\subsection{Deflection}

The deflection of FPB with notch is far greater than that without notch, as seen in Figure 7. Deflection rises by $0.07 \%$ on average for every load addition.

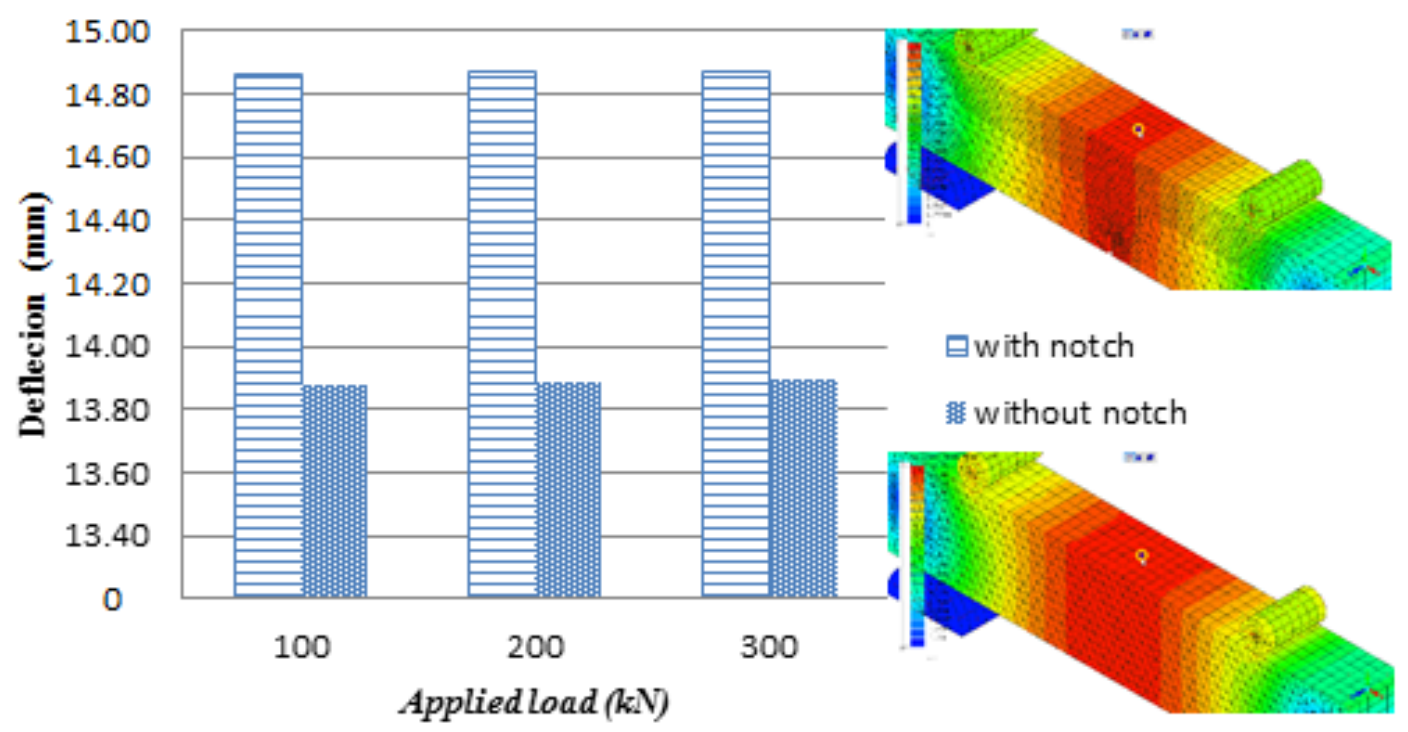

Figure 7. Deflection against load variation

\subsection{Mid-Cross-Section Deflection Analysis}

Analysis of deflection in the FPB models with notch and without notch covered the mid-cross-section area comprising the mid-top, mid-center and mid-bottom sections. All deflection patterns are similar for loads of 100, 200, and $300 \mathrm{kN}$. The deflection patterns in the mid-top section are described in Figure 8.

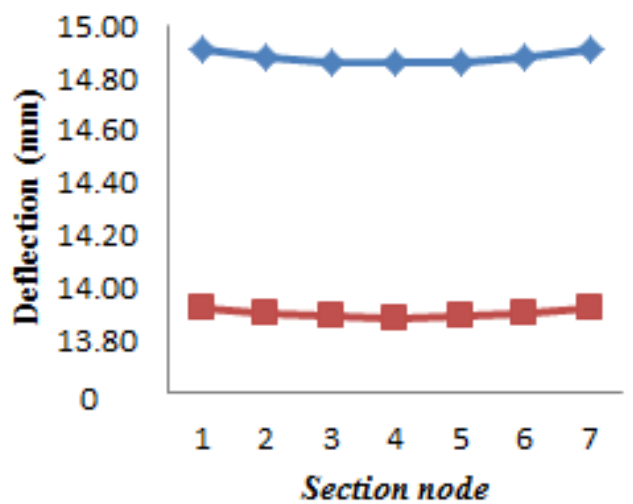

with notch $\quad-$ without notch

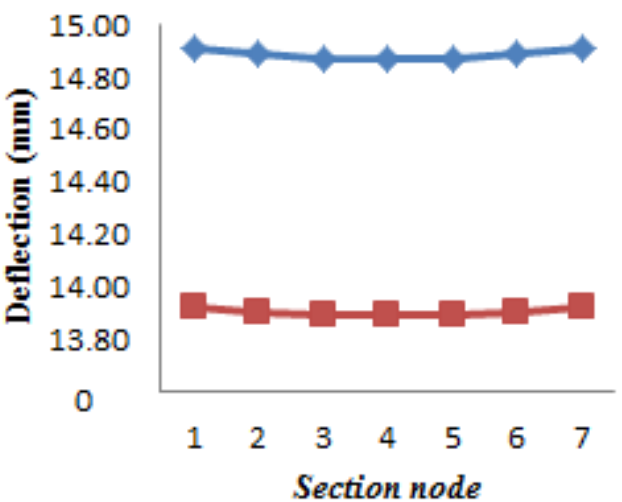

with notch $\quad-$ without notch
(a). Applied load $100 \mathrm{kN}$
(b). Applied load $200 \mathrm{kN}$ 


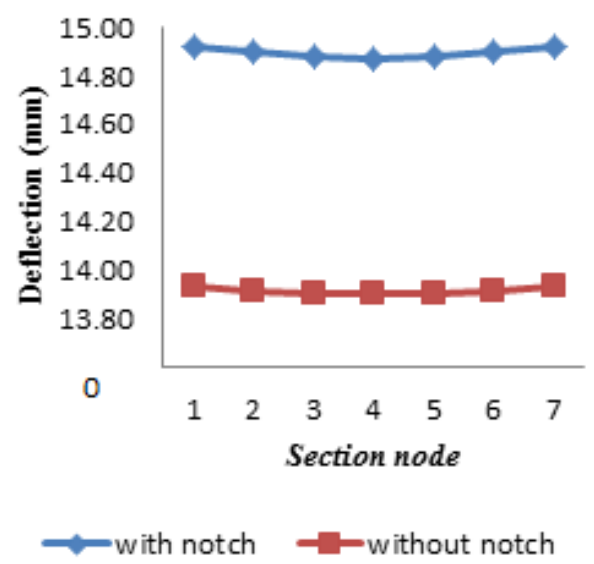

(c). Applied load $300 \mathrm{kN}$

Figure 8. Mid-top section deflection distribution patterns

Deflection analysis revealed that the model with notch has greater deflection than that without notch. The notch adds deflection by an average of $7.08 \%$. The $100 \mathrm{kN}$ load gives a $7.09 \%$ addition, while each of the $200 \mathrm{kN}$ and $300 \mathrm{kN}$ loads gives $7.08 \%$. This indicates that all loads have comparable trends of stress difference due to the notch.

\subsection{Deflection Distribution Pattern}

Figures 9 and 10 illustrate deflection with and without notch at $200 \mathrm{kN}$ load. Every FPB model received 100, 200 and $300 \mathrm{kN}$ loads for the observation of the mid-cross-section. The load variation exhibits similar deflection patterns.

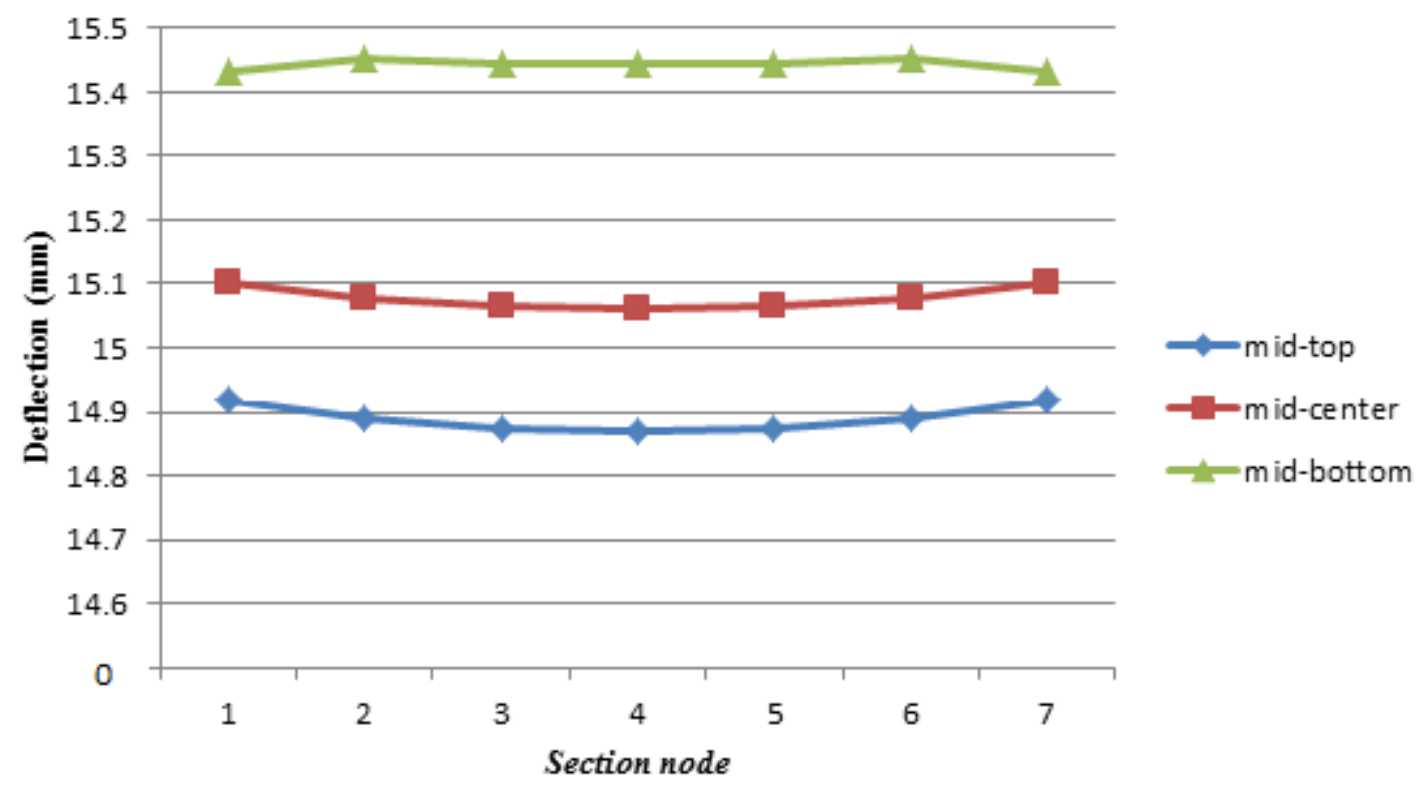

Figure 9. Deflection in FPB with notch at $200 \mathrm{kN}$ 


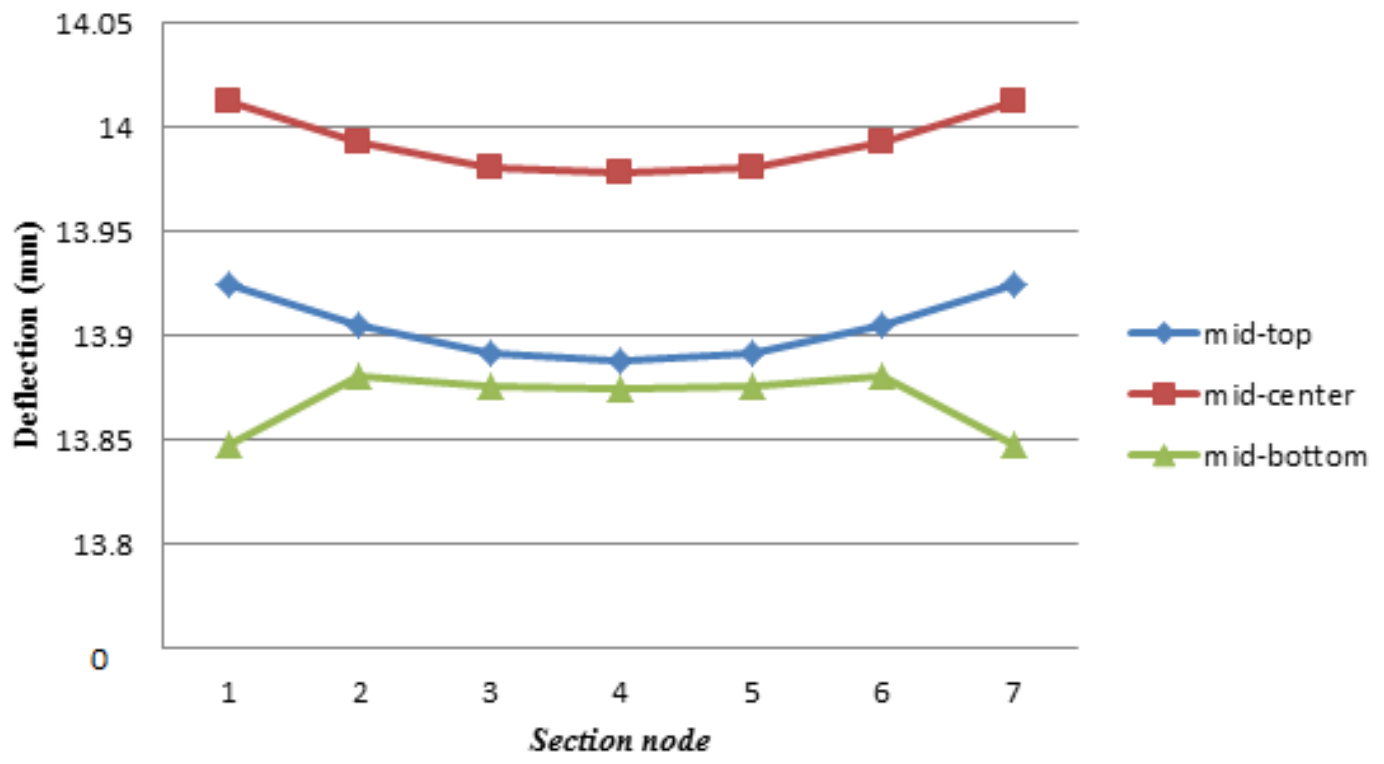

Figure 10. Deflection in FPB without notch at $200 \mathrm{kN}$

The highest deflection distribution occurs in the mid-bottom area of the FPB model with notch and in the mid-center area of the model without notch.

\subsection{Stress Distribution Pattern}

Figures 11 and 12 represent stress distribution with and without notch at $200 \mathrm{kN}$ of load. Every FPB model was subjected to loads of 100, 200 and $300 \mathrm{kN}$ to identify their influence on stress. All loads generate virtually the same pattern. For the $200 \mathrm{kN}$ load, the stress distribution in the mid-cross-section is shown in Figure 13.

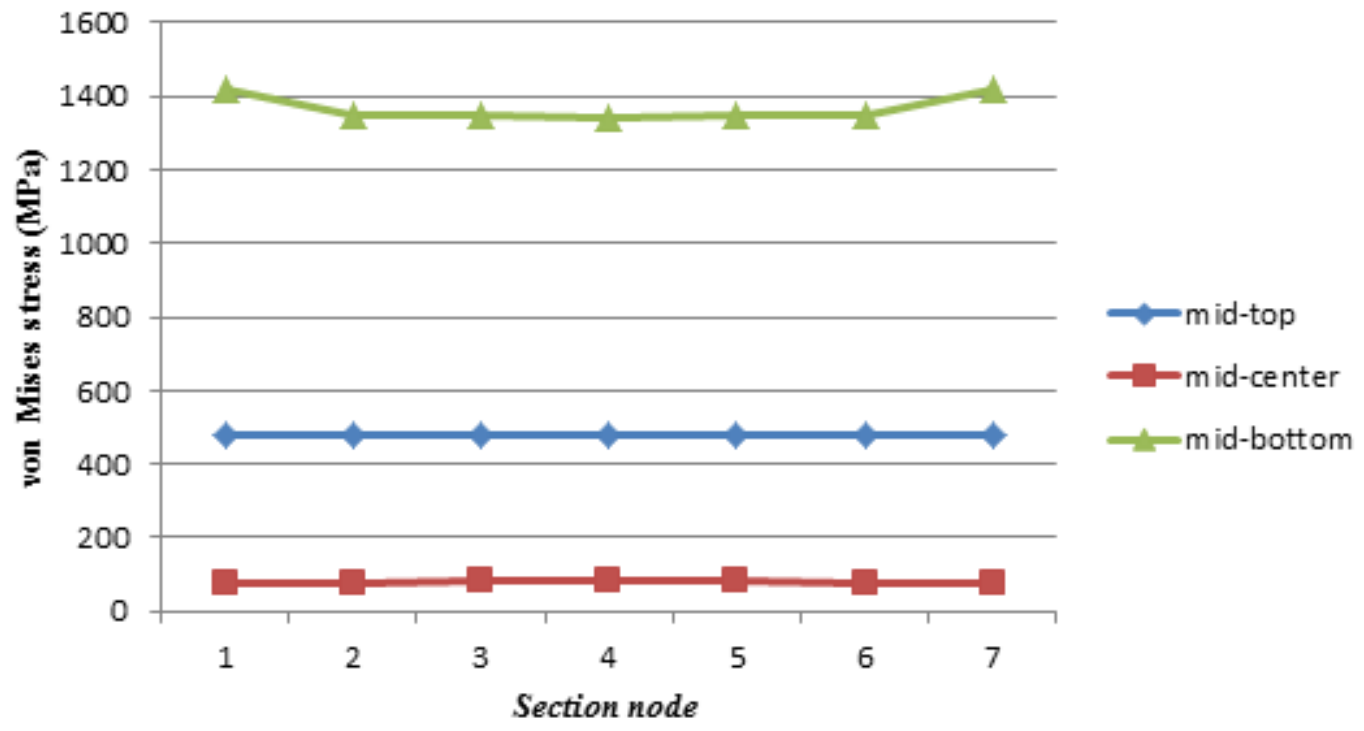

Figure 11. Von Mises stress of FPB with notch at $200 \mathrm{kN}$ 


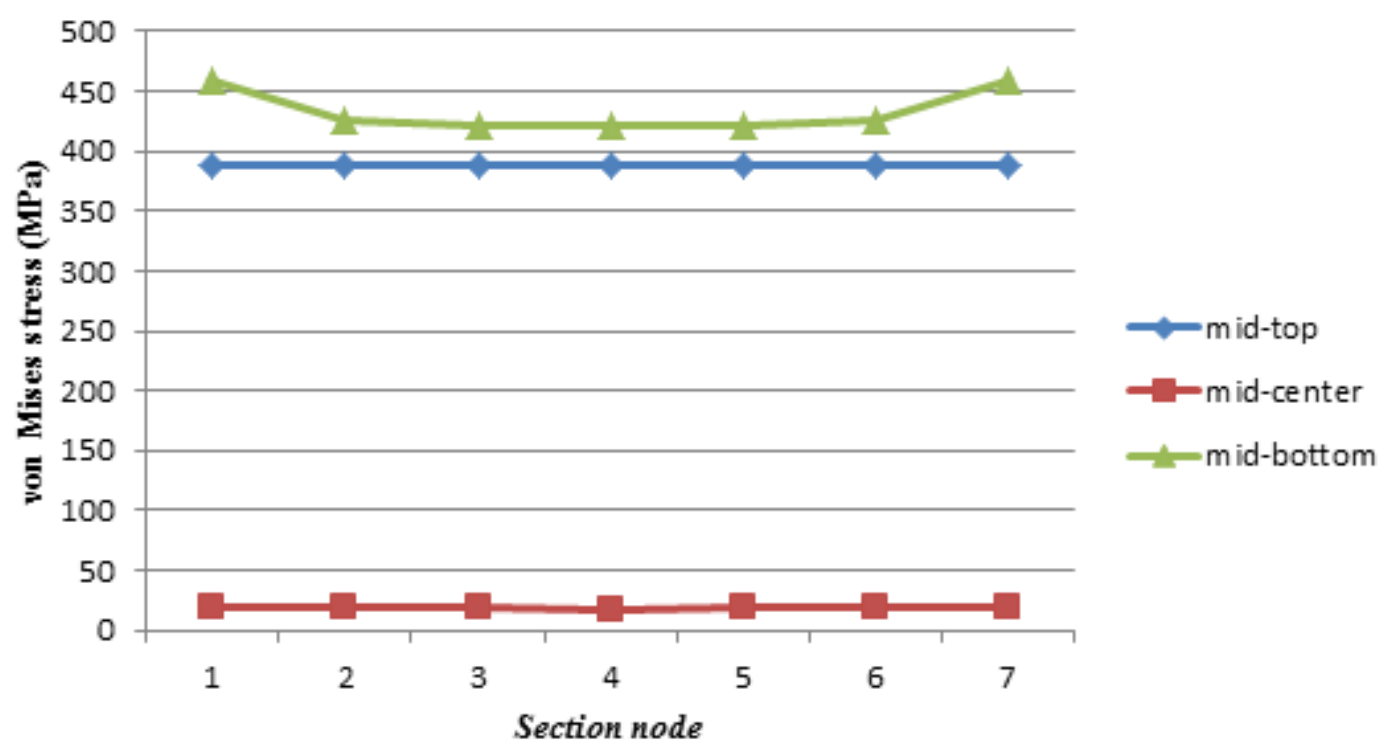

Figure 12. Von Mises stress of FPB without notch at $200 \mathrm{kN}$

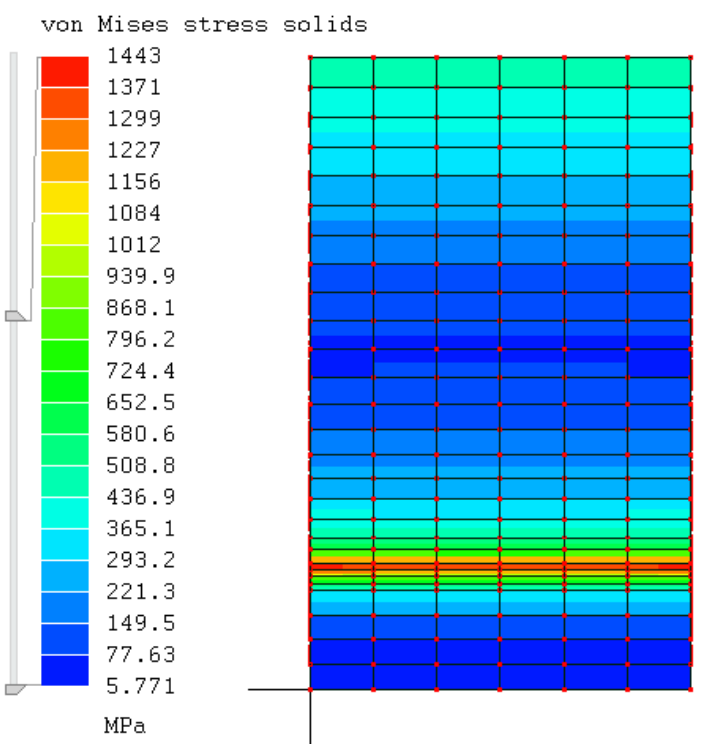

(a) FPB with notch

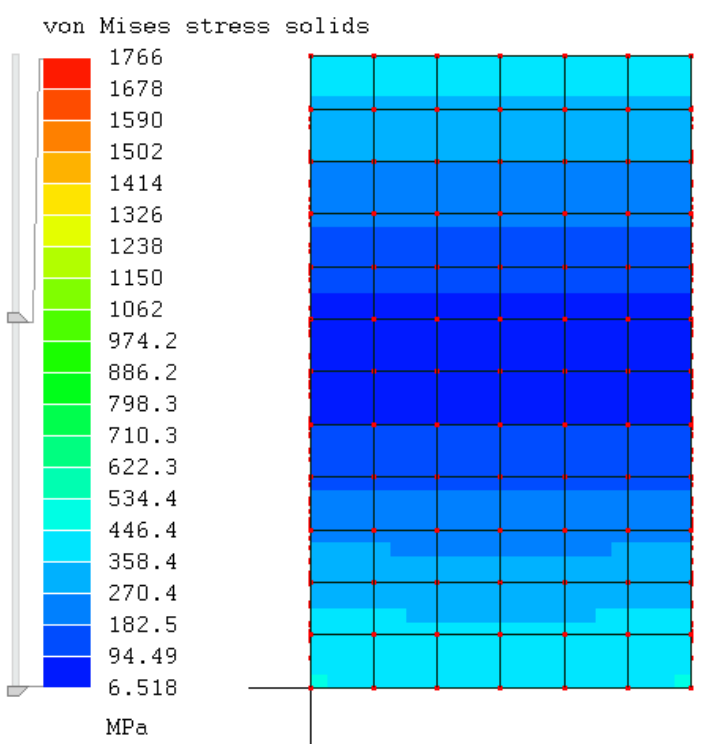

(b) FPB without notch

Figure 13. Von Mises stress in mid-cross-section area at $200 \mathrm{kN}$

The stress distribution of FPB models with and without notch at $200 \mathrm{kN}$ indicates that the mid-bottom area bears the highest stress concentration while the mid-center area holds the lowest. This signifies that the lower the area, the higher the stress becomes.

\section{Conclusions}

An FPB model simulation can be used to examine deflection and stress phenomena inside a block which cannot be observed by experiment.

The distribution of FPB deflection occurring in the mid-top, mid-center and mid-bottom sections discloses that deflection in the FPB model with notch is greater than in the model without notch.

The distribution of stress and deflection in the mid-cross-section of each FPB model reveals that stress concentration escalates toward the mid-bottom area. Meanwhile, the highest deflection of the FPB model with notch takes place in the mid-bottom area, but that of the model without notch occurs in the mid-center area.

The effects of load variation demonstrate that the von Mises stress and deflection of the FPB model with notch are greater than without notch, implicating that the greater the sustained load, the greater the von Mises stress and deflection values. 


\section{REFERENCES}

[1] Mouritz, A.P. 2012, Mechanical And Durability Testing Of Aerospace Materials, Book of Introduction to Aerospace Materials, Chapter-5, 91-127. https://doi.org/10.1533/9780 857095152.91

[2] Darmanto, Nursalim, M., Syafaat, I. 2014. Analisis Momen Lentur Material Baja Konstruksi dengan Variasi Momen Inersia dan Beban Tekan, Jurnal Momentum, 10 (1), 24-28. ISSN 0216-7395.

[3] Chung, W. H., Eamon, C.D. 2017, Laboratory Testing, Book Of Strengthening Of Concrete Structures Using Fiber Reinforced Polymers (FRP), Chapter-6, 191-211. https://do i.org/10.1016/B978-0-08-100636-8.00006-5

[4] Almusallam, T., Alsalloum, Y., Elsanadedy, H., Alshenawy, A., Iqbal, R. 2018, Behavior of FRP-Strengthened RC Blocks with Large Rectangular Web Openings in Flexure Zones: Experimental and Numerical Study, International Journal of Concrete Structures and Materials, 1-28. https://doi.org/10.1186/s40069-018-0272-5

[5] Jordaan, J.P. 2018, Four-point Bending Fatigue Test Specimen Design by FEA, R \& D Journal of the South African Institution of Mechanical Engineering, 34, 1-8. http://www.saimeche.org.za

[6] George, J., Rama, K.J.S., Kumar., M.V.N.S., Vasan, A. 2017, Behavior of Plain Concrete Block subjected to Three Point Bending using Concrete Damaged Plasticity (CDP) Model, Journal of Materials Today: Proceedings, 4, 9742-9746.

[7] Yin, Y., Qiao, Y., Hu, S. 2019, Four-Point Bending Tests For The Fracture Properties Of Concrete, Journal of Engineering Fracture Mechanics, 1-39. https://doi.org/10.1 016/j.engfracmech.2019.03.004

[8] ASTM E399. 1997. Standard Test Method for Plane-Strain Fracture Toughness of Metallic Materials, American Society For Testing And Materials, West Conshohocken, PA 19428.

[9] Salathiel, M., Leopold, M., Moyo, P. 2016, Finite Element Modeling Of Reinforced Concrete Block Patch Repaired And Strengthened With Fiber-Reinforced Polymers, International Journal of Engineering And Technical Research (IJETR), 4 (3), ISSN: 2321-0869 (O) 2454-4698.

[10] Peng, C., Guodong, L., Jiangjiang, Y., Ming, Z., Feng, J., Zhimeng, Z. 2019, Research And Application Of Random Aggregate Model In Determining The Fracture Behavior Of Four-Point Bending Block With Notch, Journal Of Construction And Building Materials, 202, 279-289. https://doi.org/10.1016/j.conbuildmat.2018.12.195

[11] Chen, X., Shi, D., Shen, N., Li, S., Liu, S. 2019, Experimental Study And Analytical Modeling On Fatigue Properties Of Pervious Concrete Made With Natural And Recycled Aggregates, International Journal of Concrete Structures and Materials, 1-13. https://doi.org/10.1186/s40 069-018-0305-0

[12] Hillerborg, A., Modéer, M., Petersson, P.-E. 1976, Analysis of crack formation and crack growth in concrete by means of fracture mechanics and finite elements, Cement and Concrete Research, 6(6), 773-781. DOI 10.1016/0008-884 6(76)90007-7

[13] Lu, W.Y., Hu, S.W. 2015, Effect Of Large Crack-Depth Ratio On Threepoint Bending Concrete Block With Single Edge Notch, Journal Of Materials Research Innovations, 19 (8), DOI 10.1179/1432891715Z.S8-3120000000001692

[14] Zhang, P., Guan, Q.Y., Liu, C.H., Li, Q.F. 2013, Study on Notch Sensitivity of Fracture Properties of Concrete Containing Nano-SiO2 Particles and Fly Ash, Journal of Nanomaterials, 2013, 1-7, http://dx.doi.org/10.1155/2013/3 81682

[15] Korte, S., Boel, V., Corte, W.D., Schutter, G.D., Seilt, S. 2013, Experimental Study Of The Influence Of The Initial Notch Length In Cubical Concrete Wedge-Splitting Test Specimens, Jurnal Of Key Engineering Materials, 525-526. doi:10.4028/www.scientific.net/KEM.525-526.209

[16] Bobinski, J., Tejchman, J., Gorski, J. 2009, Notched Concrete Blocks Under Bending - Calculations Of Size Effects Within Stochastic Elasto-Plasticity With Non-Local Softening, Journal Of Arch. Mech., 61 (3-4), 283-307.

[17] Song, L., Fan, Z., Hou, J. 2019, Experimental and Analytical Investigation of the Fatigue Flexural Behavior of Corroded Reinforced Concrete Blocks, International Journal of Concrete Structures and Materials, 1-14. https://doi.org/10. 1186/s40069-019-0340-5

[18] Ann, K.Y., Cho, C.G. 2013, Constitutive Behavior And Finite Element Analysis Of FRP Composite And Concrete Members, Journal Of Materials ISSN 1996-1944, 6, 3978-3988. doi:10.3390/ma6093978

[19] Atmojo, K. 2012, Analisa Tegangan Vonmises, Jurnal Eprints UNDIP, bab-3, 25-38.

[20] Lee, J., Lopez, M.M. 2014, An Experimental Study On Fracture Energy Of Plain Concrete, International Journal Of Concrete Structures And Materials, 8(2), 129-139. ISSN 1976-0485 / eISSN 2234-1315. DOI 10.1007/s40069-0140068-1

[21] Ding, Y., Bai, Y.L. 2018, Fracture Properties Of Alkali-Activated Slag And Ordinary Portland Cement Concrete And Mortar, Journal of Construction And Building Materials, 165, 310-320. https://doi.org/10.1016/j .conbuildmat.2017.12.202

[22] Metwally, I.M. 2015, Three-Dimensional Nonlinear Finite Element Analysis Of Concrete Deep Block Reinforced With GFRP Bars, Journal Of Housing And Building National Research Center (HBRC), 1-14. http://dx.doi.org/ 10.1016/j.hbrcj.2015.02.006

[23] Murray, Y.D., Abuodeh, A., Bligh, R. 2007, Evaluation of LS-DYNA Concrete Material Model 159, Report of Users Manual for LS-DYNA Concrete Material Model 159, FHWA-HRT-05-062 (206), 22101-2296.

[24] Hibbeler, R.C. 2008, Mechanics of Materials Seventh Edition, 12-7 (615). Nanyang Technology University, Pearson Education South Asia, Singapore. ISBN 978-0-13-220991-5.

[25] Mardaliazad, A., Scazzosi, R., Manes, A., Giglo, M. 2017, Four-Point Bending Test On A Middle Strength Rock: 
Numerical And Experimental Investigations, Journal of Frattura Ed Integrità Strutturale, 41, 504-523; DOI: 10.3221/IGF-ESIS.41.62

[26] Cao, P., Zhang, C. 2013, Using Finite Element Software to Simulation Fracture Behavior of Three-point Bending Block with Initial Crack, Journal Of Software, 8 (5), 1145-1150. doi:10.4304/jsw.8.5.1145-1150

[27] Garcia, R., Beserra, A., Dias, D.P., Assis, K.S., Mattos, O.R. 2015, Back-Face Strain Compliance Relation For SEN (B) Specimens For Wide Range In Crack Lengths, Conference Paper In NACE - International Corrosion Conference Series, 5783, 1-12. https://www.researchgate.net/publication/2816 24126 